\title{
Presepsi Ibu Tentang Asuhan Balita Oleh Mahasiswa Tingkat III Dalam Program Mitra Keluarga
}

\author{
Ranti Febriyani ${ }^{1}$, Sri Astuti ${ }^{2}$, R. Tina Dewi Judistiani ${ }^{3}$, Sefita Aryuti Nirmala ${ }^{4}$ \\ ${ }^{I}$ Program Studi Diploma IV Kebidanan Fakultas Kedokteran Universitas Padjadjaran \\ ${ }^{2}$ Divisi kesehatan ibu dan anak Departemen ilmu kesehatan masyarakat Fk Unpad \\ ${ }^{3}$ Divisi Epidemiologi dan Biostatiska Deepartemen Epidemiologi dan Biostatiska Fakultas Kedokteran Universitas \\ Padjadjaran \\ ${ }^{4}$ Divisi kesehatan ibu dan anak Departemen ilmu kesehatan masyarakat Fk Unpad.
}

\begin{tabular}{|c|c|}
\hline ARTICLE INFORMATION & A B S T R A K \\
\hline $\begin{array}{l}\text { Article Trace } \\
\text { Submission: Februari, 103, } 2019 \\
\text { Final Revision: March 25, } 2019 \\
\text { Available online: April 20, } 2019\end{array}$ & $\begin{array}{l}\text { Pelayanan kebidanan yang berkesinambungan, berfokus pada aspek } \\
\text { pencegahan, promosi kesehatan dengan berlandaskan kemitraan dan } \\
\text { pemberdayaan masyarakat. Peran dan fungsi bidan diantaranya } \\
\text { memberikan asuhan pada balita. Tujuan penelitian ini untuk mengetahui }\end{array}$ \\
\hline $\begin{array}{l}\text { Kata kunci: } \\
\text { Asuhan pada balita, kepuasan, mitra } \\
\text { keluarga }\end{array}$ & $\begin{array}{l}\text { presepsi kepuasan ibu terhadap asuhan pada balita yang diberikan } \\
\text { mahasiswa tingkat III sebagai mitra keluarga. Kepuasaan pasien } \\
\text { berdasarkan kehandalan, ketanggapan, jaminan, empati dan bukti fisik. } \\
\text { Penelitian ini merupakan penelitian kuantitatif dengan metode penelitian } \\
\text { deskriptif dengan pendekatan pontong lintang, populasi pada penelitian }\end{array}$ \\
\hline Key Word: & ini adalah keluarga asuh yang terdapat balita di Desa Cikeruh dan Desa \\
\hline $\begin{array}{l}\text { Care for toddlers, satisfaction, family } \\
\text { partners }\end{array}$ & $\begin{array}{l}\text { Cipacing, pengambilan sampel dalam penelitian ini menggunakan teknik } \\
\text { total sampling sampel yang digunakan adalah } 46 \text { ibu keluarga asuh. } \\
\text { Pengumpulan data dilakukan dengan menggunakan data primer dan }\end{array}$ \\
\hline $\begin{array}{l}\text { Contact: } \\
\text { rantifebriyani@gmail.com }\end{array}$ & $\begin{array}{l}\text { membagikan kuesioner. Hasil penelitian yang diperoleh dari } 46 \text { ibu } \\
\text { tentang kepuasaan dalam memberikan asuhan adalah } 52,2 \% \text { merasa puas } \\
\text { dan } 47,8 \% \text { tidak puas terhadap asuhan yang diberikan pada balita. } \\
\text { Berdasarkan karateristik ibu dengan pendidikan dasar merasa puas } \\
\text { sebanyak } 53,8 \% \text {, ibu yang berusia } 20-35 \text { tahun merasa puas } 83,3 \% \text { dan } \\
\text { ibu yang tidak bekerja merasa puas sebanyak } 95,8 \% \text {. Kepuasaan } \\
\text { mengenai bukti fisik } 60,9 \% \text { merasa puas dan mengenai ketanggapan } \\
58,7 \% \text { merasa puas, mengenai kehandalan } 58,7 \% \text { merasa puas, } \\
\text { mengenai empati } 52,2 \% \text { merasa puas dan mengenai jaminan } 52,2 \% \\
\text { merasa puas. Kesimpulan pada penelitian ini kepuasaan ibu keluarga } \\
\text { asuh yang merasa puas terhadap asuhan balita sebanyak } 52,2 \% \text {. Asuhan } \\
\text { yang sudah diberikan sudah sesuai dan diharapkan oleh ibu. }\end{array}$ \\
\hline
\end{tabular}

A B S T R A C T

Sustainable midwifery services, focusing on the aspects of prevention, health promotion and empowerment based on partnerships with the community. The role and function of the midwives of which gives the orphanage on toddlers. The purpose of this research is to know the presepsi of satisfaction towards the care of mothers on toddlers given student level III as a partner of the family. Our satisfaction patients based on reliability, responsiveness, assurance, empathy and physical evidence. This research is quantitative research descriptive research method with the pontong approach of latitude, the population in this research is to foster family found a toddler in the village of Cikeruh and the villages of Cipacing, sampling in the This research uses the technique of total sampling samples used are 46 mother foster family. Data collection is done using primary data and distribute questionnaires. The Research results obtained from 46 mother of our satisfaction in giving care is $52.2 \% 47.8 \%$ feel satisfied and not satisfied against the care given to toddlers. Based on the characteristics of mothers with primary education being satisfied as much as $53.8 \%$, 2035 -year-old mother was satisfied $83.3 \%$ and mothers who are not working as much satisfied $95.8 \%$. Our satisfaction about the physical evidence $60.9 \%$ were satisfied and about the response of $58.7 \%$ were 
satisfied, regarding the reliability of $58.7 \%$ were satisfied, about empathy $52.2 \%$ were satisfied and about $52.2 \%$ satisfied guarantee. Conclusions on the research of family foster mother that our satisfaction satisfied against the orphanage toddler as much as $52.2 \%$. That's already been given appropriate and expected by the mother.

\section{PENDAHULUAN}

Jumlah Angka Kematian Ibu dan Angka Kematian Bayi di Indonesia berdasarkan Survei Demografi dan Kesehatan Indonesia (SDKI) tahun 2012, AKI 359 per 100.000 kelahiran hidup. Untuk AKB mencapai 32 per 1000 kelahiran hidup. Data di Provinsi Jawa Barat, AKB sebesar 30 per 1000 kelahiran hidup. Menurut profil kesehatan Kabupaten Sumedang, AKI 23 per 100.000 kelahiran hidup, AKB 46 per 1000 kelahiran hidup. ( kemenkes, 2013)

Berdasarakan data yang diperoleh di Kecamatan Jatinangor pada tahun 2015 di 12 Desa yang ada jumlah penduduk adalah 83047. Untuk jumlah balita di Kecamatan Jatinangor pada tahun 2015 sebanyak 5319. Dari data jumlah balita yang ada akan bermanfaat untuk penelitian ini karena mempermudah dalam menentukan masalah yang sering terjadi pada masyarakat.

Hasil survei mawas diri yang dilakukan mahasiswa kebidanan pada bulan April 2016 di dapatkan beberapa masalah pada balita yang masih tinggi di 3 desa di kecamatan jatinangor yaitu, di Desa Cikeruh terdapat balita yang tidak mendapatkan Vitamin A sebanyak 24,3\%, Desa Cilayung masih terdapat gizi kurang pada balita sebanyak 2,59\%, dan untuk Desa Cipacing banyak balita yang tidak mendapatkan imunisasi lengkap pada saat bayi yaitu sebanyak $13 \%$. Untuk masalah yang sering umum terjadi di 3 desa tersebut yaitu banyaknya pemberian MP Asi dini dan kegagalan ASI Eksklusif yaitu sebanyak $26,5 \%$.

Bidan merupakan salah satu tenaga kesehatan yang memiliki posisi penting dan strategis terutama dalam penurunan AKI dan AKB. Pelayanan kebidanan yang berkesinambungan, berfokus pada aspek pencegahan, promosi dengan berlandaskan kemitraan dan perbedayaan masyarakat bersama-sama dengan tenaga kesehatan lainnya untuk senantiasa siap melayani siapa saja yang membutuhkan, maka dari itu kualitas pelayanan harus ditingkatkan . terutama asuhan yang diberikan pada balita salah satunya yaitu memberikan asuhan tumbuh kembang pada balita sesuai dengan usianya. Memberikan konseling mengenai stimulasi pertumbuhan perkembangan dan asupan nutrisi pada balita akan sangat bermanfaat pada ibu yang mempunyai balita, sehingga ibu mengetahui dan mampu menerapkan nya dalam mengasuh anaknya. Asuhan yang bermutu tinggi dan komprehensif pada balita sangat pentingnya karena akan menghasilkan kualitas hidup yang baik dan sedikit akan mengurangi angka kematian pada balita. (Unicef, 2013)

Penguatanan pelayanan sistem kesehatan dilakukan denga penguatan pada layanan promosi dan pencegahan kewenangan bidan bergerak dalam hal tersebut. Sebagai salah satu kemahiran yang harus dimiliki oleh bidan, maka sejak pendidikan mulai dilatih cara melakukan pencegahan dan promosi melalui asuhan kebidanan. Program keluarga asuh merupakan suatu kegiatan yang terintegrasi antara pendidikan dengan pengabdian masyarakat.

Presepsi klien/ masyarakat melihat layanan kesehatan yang bermutu sebagai suatu layanan kesehatan yang dapat memenuhi kebutuhan yang dirasakan dan diselenggarakan dengan cara yang sopan, santun tepat waktu, tanggap dan mampu menyembuhkan keluhannya serta mencegah berkembangnya atau meluasnya penyakit. Presepsi klien/masyarakat ini sangat penting karena klien yang merasa puas akan mematuhi pengobatan dan mau datang berobat kembali. Dimensi mutu layanan kesehatan yang berhubungan dengan presepsi kepuasaan klien dapat mengurangi kesehatan masyarakat dan kesejahtraan masyarakat. (Pohan IS; dkk, 2007)

Asuhan kebidanan yang diberikan oleh mahasiswa kebidanan meliputi berbagai aspek diantaranya adalah asuhan kehamilan, persalinan, nifas, bayi, balita, remaja, menopause, dan masalah kesehatan reproduksi yang umum terjadi pada masyarakat. Peran bidan dalam memberikan asuhan kebidanan pada balita sendiri diantaranya mengkaji kebutuhan asuhan kebidanan sesuai dengan tumbuh kembang balita, selain itu juga mampu menentukan diagnosa dan prioritas masalah, 
menyusun rencana asuhan kebidanan sesuai dengan rencana, melaksanakan asuhan sesuai dengan prioritas masalah, mengevaluasi hasil asuhan yang telah diberikan, membuat rencana tindak lanjut dan membuat catatan atau laporan asuhan. Bidan harus mampu memberikan asuhan yang bermutu tinggi, komprehensif pada balita yaitu asuhan pertumbuhan dan perkembangan balita normal, pemberian nutrisi yang baik, mencaga keselamatan balita, mencegah penyakit pada balita. (Prawiroharo S, 2008).

Dengan adanya mahasiswa yang memberikan asuhan kepada balita diharapkan dapat membantu ibu dan keluarga dalam mengasuh anaknya dengan benar dan tepat. Selain itu pentingnya presepsi ibu mengenai mahasiswa yang memberikan asuhan kepada anaknya dilihat dari kepuasaan untuk melakukan evaluasi dari program mitra keluarga tersebut.

Berdasarkan penjelasan di atas peneliti tertarik melakukan penelitian yang mengenai presepsi ibu tentang asuhan balita oleh mahasiswa tingkat III dalam program keluarga asuh, presepsi tersebut dilihat dari kepuasaan ibu. Kepuasaan tersebut meliputi kehandalan (reliability), ketanggapan (responsivencess), jaminan (assurance), empati (empahty), bukti fisik (tangible).

\section{METHOD}

Jenis penelitian ini adalah kuantitatif dengan menggunakan metode deskriptif. Desain penelitian yang digunakan adalah potong lintang dengan cara sampel diberikan kuesioner sekali dan pada waktu yang sama. Populasi pada penelitian ini adalah keluarga asuh balita yang terdaftar di Desa Cikeruh dan Cipacing pada tahun 2016 sebanyak 49 keluarga asuh. Sampel pada penelitian yaitu keluarga asuh yang mempunyai balita yang dibina oleh mahasiswa kebidanan FK UNPAD di Desa Cikeruh dan Cipacing sebanyak 46 keluarga asuh, 1 keluarga asuh sudah pindah dari Desa Cipacing dan 2 keluarga Asuh sudah pindah dari Desa Cikeruh, , teknik yang digunakan dalam penelitian ini adalah total sampling dengan menggunakan instrumen penelitian berupa kuesioner menggunakan skala likert, pengumpulan data yang digunakan dalam penelitian ini adalah data primer yang diambil dan dikumpulkan secara langsung dari responden.
Setelah pengumpulan data dilakukan pengelolaan data secara manual. Dari seluruh data yang terkumpul dilakukan penjumlahan masing-masing variabel yang diteliti kemudian dibuat persentasenya. Analisa data menggunakan analisa univariat yang dilakukan secara deskriptif dengan perhitungannya statistik sederhana berupa persentase.

Penelitian ini menggunakan izin etik melalui Komite Etik Penelitian Kesehatan Fakultas Kedokteran Universitas Padjadjaran.

\section{RESULTS}

Tabel 1. Distribusi Frekuensi Tingkat Kepuasan Ibu Berdasarkan Karakteristik

\begin{tabular}{llcccc}
\hline No & Karakteristik & \multicolumn{2}{c}{ Puas } & \multicolumn{2}{c}{ Tidak Puas } \\
\cline { 3 - 6 } 1. & Pendidikan & & F & F & \% \\
& Dasar & 14 & 58,3 & 7 & 31.8 \\
& Menengah & 9 & 37.5 & 14 & 63,6 \\
& Tinggi & 1 & 4.2 & 1 & 4.5 \\
2. & Pekerjaan & & & & \\
& Bekerja & 1 & 4.5 & 7 & 31,8 \\
& Tidak Bekerja & 23 & 95,8 & 15 & 68,2 \\
3. & Usia & & & & \\
& $<20$ tahun & 0 & 0.0 & 0 & 0.0 \\
& $20-35$ & 20 & 83,3 & 19 & 86,4 \\
& $>35$ & 4 & 16,7 & 3 & 13,6 \\
& Total & $\mathbf{2 4}$ & $\mathbf{1 0 0}$ & $\mathbf{2 2}$ & $\mathbf{1 0 0}$ \\
\hline
\end{tabular}

Berdasarkan tabel 1, dapat diketahui bahwa responden yang merasa puas dilihat dari karateristik pendidikan lebih besar pada ibu berpendidikan dasar sebanyak $58,3 \%$, responden yang merasa puas dilihat dari karateristik pekerjaan lebih besar pada ibu yang tidak bekerja sebanyak $95.8 \%$, dan responden yang merasa puas dilihat dari karateristik usia lebih besar pada ibu berusia 20-35 tahun merasa puas sebanyak $83.3 \%$.

Tabel 2. Distribusi Frekuensi Tingkat

Kepuasan Ibu mengenai kehandalan (reliability)

\begin{tabular}{ccc}
\hline $\begin{array}{c}\text { Kehandalan } \\
\text { (Reliability) }\end{array}$ & F & \% \\
\hline Puas & 27 & 58.7 \\
Tidak Puas & 19 & 41.3 \\
\hline Total & $\mathbf{4 6}$ & $\mathbf{1 0 0}$ \\
\hline
\end{tabular}


Berdasarkan tabel 2, dapat diketahui bahwa responden merasa puas yaitu 27 orang $(58.7 \%)$.

Tabel 3. Distribusi Frekuensi Tingkat Kepuasan Ibu Mengenai Ketanggapan (responsiveness)

\begin{tabular}{ccc}
\hline $\begin{array}{c}\text { Ketanggapan } \\
\text { (Responsiveness) }\end{array}$ & F & \% \\
\hline Puas & 27 & 58.7 \\
Tidak Puas & 19 & 41.3 \\
\hline Total & $\mathbf{4 6}$ & $\mathbf{1 0 0}$ \\
\hline
\end{tabular}

Berdasarkan tabel 3, dapat diketahui bahwa responden yang merasa puas yaitu 27 orang $(58.7 \%)$.

Tabel 4. Distribusi Frekuensi Tingkat Kepuasan Ibu Mengenai Jaminan (assurance)

\begin{tabular}{ccc}
\hline $\begin{array}{c}\text { Jaminan } \\
\text { (Assurance) }\end{array}$ & F & \% \\
\hline Puas & 24 & 52.2 \\
Tidak Puas & 22 & 47.8 \\
\hline Total & $\mathbf{4 6}$ & $\mathbf{1 0 0}$ \\
\hline
\end{tabular}

Berdasarkan tabel 4, dapat diketahui bahwa responden merasa puas yaitu 24 orang $(52.2 \%)$.

Tabel 5. Distribusi Frekuensi Tingkat Kepuasan Ibu Mengenai Empati (empathy)

\begin{tabular}{ccc}
\hline Empati (Empathy) & F & \% \\
\hline Puas & 24 & 52.2 \\
Tidak Puas & 22 & 47.8 \\
\hline Total & $\mathbf{4 6}$ & $\mathbf{1 0 0}$ \\
\hline
\end{tabular}

Berdasarkan tabel 5, dapat diketahui bahwa responden merasa puas yaitu 24 orang $(52.2 \%)$.

Tabel 6.

Distribusi Frekuensi Tingkat Kepuasan Ibu Mengenai Bukti Fisik (tangible)

\begin{tabular}{ccc}
\hline $\begin{array}{c}\text { Bukti Fisik } \\
\text { (Tangible) }\end{array}$ & F & \% \\
\hline Puas & 28 & 60.9 \\
Tidak Puas & 18 & 39.1 \\
\hline Total & $\mathbf{4 6}$ & $\mathbf{1 0 0}$ \\
\hline
\end{tabular}

Berdasarkan tabel 6, dapat diketahui bahwa responden merasa puas yaitu 28 orang $(60.9 \%)$.

Berdasarkan tabel 1, di dapatkan hasil bahwa sebagian besar responden ibu keluarga asuh merasa puas yaitu sebanyak 24 orang $(52,2 \%)$ dan ibu yang merasa tidak puas sebanyak 22 orang $(46,8 \%)$. Dilihat dari karateristik pendidikan, ibu yang merasa puas lebih banyak pada yang berpendidikan dasar yaitu sebanyak 14 responde $(58,3 \%)$.

Menurut teori yang ada, pendidikan yang lebih tinggi cenderung meningkatkan kesadaran akan status kesehatan. Perbedaan tingkat pendidikan akan memiliki kecenderungan yang berbeda dalam pemanfaatan pelayanan kesehatan. (Notoadmojo S, 2009)

Hasil dari data yang di dapatkan dalam penelitian ini bahwa pendidikan berpengaruh terhadap respon ibu dalam penerimaan informasi, pengetahuan tentang kesehatan maupun asuhan pada balita. Dalam penelitian ini di dapatkan ibu yang berpendidikan dasar merasa puas terhadap adanya mahasiswa tingkat III. Keluarga dengan latar belakang pendidikan rendah akan sangat lebih membutuhkan mahasiswa sebagai mitra keluarga karena dengan adanya asuhan balita akan membantu ibu dalam hal memberikan asuhan yang sesuai kebutuhan kepada anaknya dan bertambah nya pengetahuan ibu dalam segi kesahatan pada balitanya. Sehingga diharapkan ibu yang tingkat pendidikan dasar lebih menyadari arti kesehatan dan memanfaatkan pelayanan posyandu bagi anaknya.

Pada hasil penelitian yang diperoleh menunjukan bahwa sebagian besar responden ibu keluarga asuh yaitu berumur 20-35 tahun sebanyak 39 orang responden $(84,8 \%)$, usia $>35$ tahun sebanyak 7 responden $(15,2 \%)$, sedangkan untuk usia $<20$ tahun tidak terdapat responden. Dari karateristik usia di dapatkan ibu yang merasa puas adalah ibu yang usianya 20-35 tahun sebanyak 20 responden $(83,3)$.

Menurut teori kebutuhan seseorang terhadap suatu barang atau jasa akan semakin meningkat seiring bertambahnya usia. Umur seseorang juga dapat menggambarkan kematangan seseorang dalam menentukan tindakan dari kehidupannya (surjono, 2005). Semakin tua usia responden bertambah semakin matang pula dalam 
menentukan suatu pilihan. (Notoadmojo S, 2009)

Hasil penelitian ini menunjukan bahwa presepsi kepuasaan ibu usia 20-35 tahun merasa puas terhadap adanya mahasiswa tingkat III sebagai mitra keluarga. Dapat di simpulkan bahwa usia dapat mempengaruhi kepuasaan ibu karena semakin tua usia ibu semakin banyak pengalaman dalam memberikan asuhan pada anaknya. Ibu yang berusia 20-35 tahun masih kurang pengalaman dalam memberikan asuhan pada balita, sehingga ibu yang berusia 20-35 tahun membetuhkan pengetahuan agar asuhan yang diberikan kepada anaknya sesuai dan benar.

Pada hasil penelitian yang diperoleh menunjukan bahwa sebagian besar responden ibu keluarga asuh yaitu ibu yang tidak bekerja sebanyak 38 responden $(82,6 \%)$, dan untuk ibu yang bekerja 8 responden $(17,4 \%)$. Dilihat dari karateristik pekerjaan ibu yang tidak bekerja merasa puas sebanyak $95,8 \%$

Menurut teori pekerjaan akan mempengaruhi status ekonomi seseorang. Seseorang yang berpenghasilan di atas rata-rata mempunyai minat yang lebih tinggi dalam memilih pelayanan kesehatan. (Notoadmojo S, 2009)

Hasil penelitian ini menunjukan bahwa presepsi ibu yang tidak bekerja di ukur dari kepuasaan yaitu merasa puas dengan adanya mahasiswa tingkat III dapat mempermudah dalam menyelesaikan masalah yang terjadi pada balitanya, selain itu mempermudah ibu dalam memperoleh informasi mengenai pemberian asuhan yang benar sehingga ibu tidak perlu pergi ketenaga kesehatan dan tidak perlu mengeluarkan biaya untuk memperoleh informasi keehatan tentang balitanya.

Berdasarkan tabel 2, hasil penelitian ini menunjukan bahwa sebagian besar presepsi ibu keluarga asuh dilihat dari kepuasan, menilai asuhan pada balita yang diberikan mahasiswa tingkat III dilihat dari kehandalan (reliability) yaitu yang mengatakan puas terhadap asuhan pada balita sebanyak 27 responden $(58,7 \%)$, dan untuk yang tidak puas sebanyak 19 orang $(41,3 \%)$.

Kehandalan adalah kemampuan untuk memberikan pelayanan sesuai dengan yang dijanjikan secara segara, akurat dan terpercaya. (Rangkuti; dkk, 2008) (Desimawati; dkk, 2013)

Dalam dimensi ini mahasiswa tingkat III dituntut untuk menyediakan asuhan dan pelayanan yang handal, terpercaya dan akurat. Menurut Handi Irawan dalam saragih (2009) sekitar $60 \%$ dari keluhan klien yang menerima pelayanan di tempat pelayanan kurang puas karena tidak menempati janji dan melakukan kesalahan dalam memberikan pelayanan. (Handi IR, 2009)

Hasil penelitian ini di dapatkan presepsi kepuasaan ibu keluarga asuh, merasa puas terhadap asuhan balita yang diberikan mahasiswa tingkat III dilihat dari teori dan isi dari kuesioner. Bahwa pelayanan yang di berikan dilihat dari ketelitian , kesabaran mahasiswa tingkat III dalam memberikan asuhan, selain itu juga mahasiswa selalu memberikan informasi sebelum dan sesudah dilakukan pemeriksaan, saat memberikan dan mengajarkan cara perawatan yang baik dan benar pada balita sampai ibu merasa paham. Pada hasil penelitian ibu yang merasa tidak puas sebanyak $41,1 \%$, pelayanan yang tidak puas juga terdapat mengenai kunjungan dan pemantauan yang dijanjikan sebelumnya oleh mahasiswa tingkat III tidak sesuai atau tidak tepat waktu, dan kurangnya tanggapan ketika ibu mengeluh masalah yang terjadi pada balitanya.

Berdasarkan penjelasan sebelumnya terhadap kehandalan sesuai dengan peran dan fungsi bidan dalam memberikan asuhan yaitu bidan dituntut untuk teliti, penuh kesabaran, memberikan informasi dan konseling sesuai kebutuhan pasien serta melakukan pemantauan pertumbuhan dan perkembangan balita dengan pemberian asuhan berkelanjutan. (Sofyan; dkk, 2008).

Berdasarkan tabel 3, hasil penelitian menunjukan bahwa sebagian besar presepsi ibu keluarga asuh dilihat dari kepuasaan, menilai asuhan pada balita yang diberikan bidan muda dilihat dari dimensi daya tanggap (reponsiveness), yang merasa puas sebanyak 27 orang $(58,7 \%)$ dan untuk yang tidak puas sebanyak 19 orang $(41,3 \%)$.

Daya tanggap adalah kemampuan untuk membantu konsumen dan memberikan pelayanan dengan cepat dan baik. Menurut Wike Diah (2009) 87,1\% merasa puas pada jawaban atas pertanyaan bahwa perawat tepat dan 
tanggap dalam memberikan kebutuhan pasien. ( Wike Diah, 2009)

Dapat di disimpulkan bahwa ketanggapan yang dimiliki mahasiswa tingkat III sudah sesuai dengan apa yang diharapkan oleh ibu keluarga asuh di lihat hasil data yang di dapatkan dari kuesioner. Mahasiswa tingkat III memberikan asuhan yang aman, mendengarkan keluhan dan masalah mengenai permasalahan yang dialami, sampai memberikan asuhan yang baik dan mampu menjelaskan kemana ibu harus pergi untuk mendapatkan layanan rujukan. Pada hasil penelitian juga terdapat ibu yang merasa tidak puas terhadap pelayanan yang diberikan oleh mahasiswa tingkat III yaitu sebanyak $41,3 \%$, pelayanan yang dirasakan tidak puas mengenai ketanggapan mahasiswa belum mampu mengatasi kegelisahan pada saat anaknya di periksa, belum mampu memberikan alternatif asuhan pada anaknya dan keterampilan dalam melayani pasien.

Berdasarkan penjelasan sebelumnya terhadap ketanggapan yang dimiliki mahasiswa tingkat III sesuai dengan peran dan fungsi bidan dalam memberikan asuhan kebidanan pada balita salah satunya adalah peran sebagai pelaksana, diantaranya tugas mandiri bidan mengkaji kebutuhan asuhan pada balita dengan cara mendengarkan keluhan yang di ungkapkan oleh ibu, menyusun rencana asuhan, melaksanakan asuhan sesuai dengan masalah yang dialami. Selain itu juga tugas kolaborasi, bidan dalam menangani kasus balita dengan resiko tinggi, komplikasi maupun kegawatdaruratan yang terjadi memerlukan tindakan kolaborasi, mahasiswa tingkat III menjelaskan kemana ibu harus pergi untuk mendapatkan pelayanan rujukan termasuk ke dalam tugas kolaborasi dan tugas merujuk. (Sofyan; dkk, 2008)

Berdasarkan tabel 4, hasil penelitian menunjukan sebagian besar presepsi ibu keluarga asuh dilihat dari kepuasaan, yang menilai asuhan pada balita yang diberikan mahasiswa tingkat III dilihat dari dimensi berdasarkan jaminan (assurance), di dapatkan ibu yang merasa puas sebanyak $24 \mathrm{ibu}$ $(52,2 \%)$ dan yang merasa tidak puas adalah 22 ibu $(47,8 \%)$

Jaminan merupakan pelayanan yang berhubungan dengan kemampuan dalam menanamkan kepercayaan dan keyakinan pada pasien. Jaminan di dalamnya meliputi pengetahuan terhadap pemberi layanan dan keterampilan dalam memberikan keamanan.(Rangkuti; dkk, 2008)

Dari hasil penelitian Agustinus (2013) untuk konsumen kesehatan, aspek ini berbicara masalah reputasi institusi kesehatan yang dituju pasien, reputasi dilihat dari pengetahuan, keterampilan, kepercayaan pasien. Apabila reputasi yang dihasilkan pasien baik, maka pasien tidak hanya puas, pasien akan loyal karena merasa harapannya terpenuhi saat membutuhkan keberadaan instiusi kesehatan. (Agustinus, 2013)

Hasil penelitian yang sudah dilakukan, ibu merasa puas terhadap asuhan pada balita yang berkaitan dengan jaminan, dilihat dari data yang di dapat dan kuesioner, mahasiswa tingkat III mampu membuat ibu lebih tenang dalam melakukan asuhan pada balitanya dan apabila ada keluhan yang dirasakan oleh balita ibu mampu mengatasinya. Dengan mempunyai pengetahuan mengenai asuhan kebidanan pada balita sehingga ibu yakin dan percaya. Pada hasil penelitian juga terdapat ibu yang merasa tidak puas sebanyak $47,8 \%$. terhadap pelayanan yang diberikan mahasiswa tingkat III, adanya ketidakpuasan ibu dilihat dari jawaban dari kuesioner yang telah di isi, ibu merasa tidak puas karena mahasiswa tidak dapat menjelaskan kesulitan apa yang akan terjadi dalam menjalankan asuhan pada anaknya dan mahasiswa tingkat III tidak memberikan no telepon untuk mengubunginnya ketika ada masalah pada anaknya, sehingga ibu merasa kesulitan dalam berkonsultasi dengan bidan muda. (Laksono; dkk, 2012)

Berdasarkan penjelasan sebelumnya mengenai jaminan yang harus dimiliki oleh mahasiswa tingkat III yang sesuai dengan kompotensi yaitu bidan harus mempunyai pengetahuan dasar tentang balita yang diantaranya mengenai prinsip-prinsip asuhan, masalah-masalah yang mungkin terjadi pada balita, penyakit-penyakit pada balita, penyimpangan pertumbuhan perkembangan pada balita serta penatalaksanaan dan bahaya-bahaya yang sering terjadi serta upaya pencegahannya. Selain itu pentingnya memiliki keterampilan dasar diantaranya melaksanakan pemantauan dan stimulasi tumbuh kembang, melaksanakan penyuluhan mengenai asuhan balita, melakukan pemeriksaan berkesinambungan. Kurangnya pengetahuan 
mengenai asuhan balita pada mahasiswa tingkat III tidak terlepas dari kedudukannya sebagai mahasiswa yang masih memerlukan bimbingan dari staf pengajar dan pengalaman yang lebih banyak untuk bisa memberikan pelayanan dengan baik dan terampil. (Sofyan; dkk, 2008)

Berdasarkan tabel 5, hasil penelitian menunjukan sebagian besar presepsi ibu keluarga asuh dilihat dari kepuasaan, menilai asuhan pada balita yang diberikan mahasiswa tingkat III dilihat dari dimensi berdasarkan empati (Emphaty) di dapatkan ibu yang merasa puas sebanyak $24 \mathrm{ibu}$ $(52,2 \%)$ dan yang merasa tidak puas adalah 22 ibu $(47,8 \%)$.

Empati adalah kesedian untuk peduli dan memberikan perhatian yang tulus dan bersifat pribadi kepada pasien. Dimensi empati adalah dimensi yang memberikan peluang besar untuk menciptakan pelayanan yang surprise yaitu sesuatu yang tidak diharapkan pengguna jasa tetapi diberikan oleh penyedia.(Diman A, 2015)

Data dari penelitian yang sudah dilakukan, asuhan yang dilihat dari empati sudah diberikan dengan baik, dilihat dari hasil kepuasaan ibu merasa puas, mahasiswa bersikap sopan, ramah dalam memberikan asuhan, selain itu mahasiswa menempatkan dirinya sederajat dengan ibu sehingga ibu tidak merasa di ajari, . Mahasiswa tingkat III sudah menerapkan rasa peduli dan perhatian selama melakukan asuhan pada balita. Terdapat $47,8 \%$ ibu merasa tidak puas terhadap pelayanan yang diberikan mahasiswa tingkat III dikarenakan mahasiswa tidak bersikap terbuka dan kurang pemahaman mengenai masalah yang ibu keluhkan, sehingga ibu merasa tidak bebas untuk mengutarakan masalah yang di alami pada anaknya.

Berdasarkan penjelasan yang sudah dibahas sebelumnya dalam dimensi empati sesuai dengan peran dan fungsi bidan dalam memberikan asuhan pada balita yaitu bidan di tuntut untuk bersikap terbuka, sopan, ramah, dan sederajat dengan ibu ketika memberikan asuhan balita, serta mampu memahami masalah yang dialami sehingga dapatkan terselasaikan dengan baik dan tepat masalah tersebut.

Berdasarkan tabel 6, hasil penelitian menunjukan bahwa sebagian besar presepsi ibu keluarga asuh dilihat dari kepuasaan, menilai asuhan pada balita yang diberikan bidan muda dilihat dari dimensi berdasarkan tangible, di dapatkan ibu yang merasa puas sebanyak $28 \mathrm{ibu}(60,9 \%)$ dan yang merasa tidak puas adalah $18 \mathrm{ibu}(39,1 \%)$.

Bukti fisik meliput penampilan fisik pemberi pelayanan seperti pakaian yang bersih, sopan dan alat pemeriksaan yang lengkap. Penampilan yang baik adalah penampilan yang menarik, dan pasti ditunjang dengan fasilitas yang dimiliki tim medis dirumah sakit maupun institusi kesehatan, dengan kesan yang rapi, bersih, dan itu bisa ditingkatkan melalui seragam dan kelengkapannya sebagai cermin penerimaan yang baik, agar sesuai harapan pasien yang diinginkan. (Agustinus, 2013)

Penelitian yang sudah dilakukan di dapatkan data bahwa banyak ibu yang merasa puas terhadap bukti fisik mahasiswa tingkat III dalam memberikan asuhan pada balita dilihat dari kuesioner. mahasiswa berpenampilan rapih dan bersih, bahasa yang digunakan mudah dimengerti, saat memberikan konseling mahasiswa tingkat III memakai gambar yang menarik dan jelas, sehingga ibu mengerti dan paham akan koseling yang diberikan, saat memberikan asuhan mahasiswa tampak terampil penampilan mahasiswa tingkat III sudah sesuai dengan yang diharapkan. Pada hasil penelitian juga terdapat ibu yang merasa tidak puas terhadap pelayanan yang diberikan mahasiswa tingkat III yaitu $39,1 \%$ adanya ketidakpuasaan ibu terhadap pelayanan yang diberikan yaitu mahasiswa tingkat III tidak membawa alat pemeriksaan saat melakukan kunjungan.

Berdasarkan penjelasan sebelumnya terhadap bukti fisik sesuai dengan kompotensi, melakukan pemeriksaan fisik, melakukan pemantauan dan menstimulasi tumbuh kembang balita menggunakan alat yang sesuai dan dapat digunakan dalam pemeriksaan tersebut, serta memberikan penyuluhan mengenai asuhan balita kepada ibu dengan menggunakan alat demonstrasi berupa gambar yang menarik dan sesuai dengan kebutuhan ibu.

\section{KESIMPULAN}

Berdasarkan hasil penelitian dan pembahsan mengenai presepsi kepuasaan ibu terhadap asuhan pada balita yang diberikan mahasiswa tingkat III sebagai mitra keluarga pada bulan agustus 2016 dapat disimpulkan sebagian besar ibu merasa puas yaitu sebanyak 24 responden 
(52,2\%). Kepuasan sesuai karateristik ibu diantaranya dilihat dari pendidikan, ibu yang berpendidikan dasar lebih merasa puas sebanyak $58,3 \%$, dilihat dari pekerjaan ibu yang tidak bekerja lebih merasa puas sebanyak 95,8\%, dilihat dari usia, ibu yang berusia 20-35 tahun merasa lebih puas sebanyak $83,3 \%$. Selain itu kepuasan ibu keluarga asuh dilihat dari berbagai dimensi diantaranya kehandalan $58,7 \%$ yang merasa puas, ketanggapan $58,7 \%$, jaminan $52,2 \%$ yang merasa puas , empati $52,2 \%$, dan untuk bukti fisik $60,9 \%$. Presentasi presepsi ibu yang merasa puas masih belum berbeda jauh dengan presentasi presepsi ibu yang tidak merasa puas sehingga asuhan yang diberikan lebih ditingkatkan kembali dengan cara kompotensi yang dimiliki oleh mahasiswa tingkat III lebih baik lagi dengan bimbingan dan pembelajaran yang diberikan oleh tenaga pengajar di tingkatkan kembali dalam hal memberikan asuhan.

\section{REFERENSI}

RSUD Daya. Kepuasaan pasien umum tentang kualitas pelayanan pada instalasi rawat inap RSUD Daya Makasar tahun 2013.

Data dan informasi dan kesehatan Provinsi Jawa Barat In: Indonesia kkR, editor. Bandung: Kementrian kesehatan Republik Indonesia 2013.

Desimawati, Dian Wahyuni, 2013, Hubungan Layanan Keperawatan Dengan Tingkat Kepuasan Pasien Rawat Inap : diakses 18 Maret 2015)

Diah A, 2009. Kepuasaan pasien rawat inap terhadap pelayanan perawat di RSUD Tugurejo.

Diman A, 2015. Hubungan pelayanan kesehatan dengan kepuasaan pasien di instalasi rawat inap kelas II rumah sakit umum daerah Sekayu; Diakses pada bulan agustus januari 2016.

Kesehatan ibu dan anak. In: Unicef, editor. Jakarta: Unicef; 2013.

Laksono, Ismawan N., 2008. Analisis kepuasan dan hubungannya dengan loyalitas pasien rawat inap di rumah sakit dedi jaya. Tesis diterbitkan Program Pasca sarjana Universitas Diponegoro Semarang; diakses pada tanggal 18 september 2012

Mother's day. In: Indonesia KkR, editor. Jakarta: Pusat data dan informasi kementrian kesehatan RI; 2014.

Notoadmojo S, Pendidikan dan perilaku kesehatan. Jakarta : Rineka Cipta ; 2009

Pohan IS. Jaminan mutu layanan kesehatan dasar-dasar pengertian dan penerapan Jakarta: EGC; 2007 : 13-30

Prawiroharjo S, Ilmu kebidanan. Jakarta : PT Bina Pustaka Sarwono Prawirohardjo; 2008 : 97-100.

Rangkuti, Freddy. Mearsuring customer satisfaction gaining customer relationship strategy. Jakarta : Gramedia Pustaka Utama : 2008

Santosa PW, Hidayat, Ayat. Riset terapan teori dan aplikasi, mahir menggunakan metode statistika untuk penelitian ilmiah. Jakarta ; PT Globalstant solusi utama; 2014.

Sofyan M, Siahaan R, Madjid N A, dkk. Bidan menyongsong masa depan. Jakarta: PP IBI; 2006: 114-124, 132-138 